\title{
Plant Regeneration from Callus Derived from Immature Embryo Cotyledons of Prunus mume
}

\author{
G.G. Ning and M.Z. Bao ${ }^{1}$ \\ Key Laboratory of Horticultural Plant Biology, Ministry of Education, \\ College of Horticulture and Forestry Sciences, Huazhong Agricultural \\ University, Wuhan 430070, P.R. China
}

Additional index words. shoot regeneration, organogenesis, half-strength MS medium, tissue culture

\begin{abstract}
A regeneration protocol for Prunus mume sieb.et Zucc was developed through indirect organogenesis. Immature cotyledons were excised from the open-pollinated seeds of two cultivars and cultured on a modified MS medium supplemented with various combinations of plant growth regulators. Shoot-organogenic calli were induced on halfstrength MS medium supplemented either with combinations of $2.2 \mu \mathrm{M}$ benzyladenine (BA), 5.4 to $10.8 \mu M$ 1-naphthaleneacetic acid (NAA), and 0 to $5.0 \mu M$ indolebutyric acid (IBA) or with combinations of $2.2 \mu \mathrm{M}$ BA, 4.5 to $9.0 \mu \mathrm{M}$ dichlophenoxyacetic acid (2,4-D), and 0 to $5.0 \mu \mathrm{M}$ IBA. High frequencies of shoot regeneration $(81.5 \%$ and $91.3 \%$ in $P$. mume cvs. Lv'e and Xuemei, respectively) were obtained from smooth-white nodular calli cultured on a half-strength MS medium supplemented with $2.2 \mu \mathrm{M}$ BA, $2.2 \mu \mathrm{M}$ thidiazuron, and $1.0 \mu \mathrm{M}$ IBA. A high rate of rooting $(90.2 \%$ and $88.9 \%$ in ' $\mathrm{Lv}$ ' $\mathrm{e}$ ' and 'Xuemei', respectively) occurred when shoots were cultured on WPM supplemented with

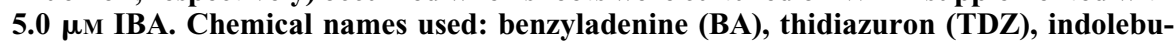
tyric acid (IBA), dichlophenoxyacetic acid (2,4-D), 1-naphthaleneacetic acid (NAA).
\end{abstract}

Prunus mume is a beautiful deciduous tree with fragrant flowers that blooms very early in the spring. It is renowned for its attractive blossoms and longevity throughout China and Japan. In addition, $P$. mume has medical value (Dogasaki et al., 2004) with "pickled plums," made from the unripe fruits of $P$. mume, being used to treat vomiting and fever (Chen, 1962). As a result of its economic importance as an ornamental and medicinal tree, there is significant interest in breeding elite varieties of $P$. mume, and this has primarily focused on using molecular markers to identify desirable phenotypes and characterizing the mechanism of selfincompatibility (Entani et al., 2003; Tao et al., 2000).

During the last 2 decades, efficient in vitro culture systems have been developed for various species of the Prunus genus. The majority of these have been achieved by inducing regeneration from either immature tissues (Hashmi et al., 1997; Hokanson and Pooler, 2000; Mante et al., 1989; Pooler and Scorza, 1995; Tang. et al., 2000) or mature explants (Andrea and Johannes, 2005; Bhagwat and

Received for publication 30 Nov. 2006. Accepted for publication $1 \mathrm{Feb} .2007$.

We thank all present and past colleagues of our laboratory for constructive discussion and technical support. We are also grateful to all the staff of the Wuhan P. mume garden, China, for providing experimental materials and Alex McCormac of England for critical reading and editing of the $m$ anuscript.

${ }^{1}$ To whom reprint requests should be addressed; e-mailwhnobleman2004@yahoo.com.cn
David, 2004; Cheong and Pooler, 2004; Declerck and Korban, 1996; Gentile et al., 2002; Hammatt and Grant,.1998; Neil and Neil, 2000; Olaya et al., 2000). For P. mume, an in vitro culture system has been reported for the induction of callus, but plant regeneration was not achieved (Liu and Chen, 1999). Although it is possible to conduct traditional breeding programs in $P$. mume, particularly with the assistance of molecular markers, this is a protracted process because of the long intergeneration times. Therefore, to accelerate the genetic improvement of $P$. mume, genetic engineering appears to be an attractive option allowing the introduction of heterologous genes for the enhancement of ornamental or other valued characteristics. Efficient plant regeneration from in vitro cultures is essential for the genetic transformation of $P$. mume. However, to date, there are very few reports of the successful regeneration of plants from cultures of P. mume.

This article presents the first report of the successful regeneration of plants of $P$. mume achieved through indirect organogenesis from cotyledons of immature embryos. In the course of this work, we also investigated the effects of the original explant source and the light environment on the rate of shoot organogenesis from callus cultures.

\section{Materials and Methods}

Plant material. Open-pollinated, immature seeds $(\approx 40$ to $50 \mathrm{~d}$ after pollination) were collected from two mature trees of $P$. mume cultivars, Xuemei and Lv'e. The trees had been growing in the Wuhan Mei flower garden (Wuhan, P.R. China) for over 10 years at the time of seed collection during Apr. and May 2005. The seeds were stored at $4{ }^{\circ} \mathrm{C}$ until use. After being washed thoroughly with running tap water for $30 \mathrm{~min}$, the immature seeds were disinfected by immersion in $70 \%$ $(\mathrm{v} / \mathrm{v})$ ethanol for 30 to $60 \mathrm{~s}$ followed by one wash in sterile water, then immersion and agitation in a $0.1 \%(\mathrm{w} / \mathrm{v})$ aqueous solution of $\mathrm{HgCl}_{2}$ for $20 \mathrm{~min}$, followed by three washes in sterile water. Cotyledons were aseptically excised and placed horizontally on the medium for callus induction. To investigate the effect of the original explant source on callus induction and subsequent plant regeneration, individual cotyledons were divided into proximal or distal sections with the embryonic axis removed.

Culture initiation and plant regeneration. The basal medium consisted of half-strength MS medium (Murashige and Skoog, 1962) supplemented with $3 \%(\mathrm{w} / \mathrm{v})$ sucrose and $0.8 \%(\mathrm{w} / \mathrm{v})$ agar (Sigma A1296, Sigma, St. Louis). This was supplemented with various combinations of plant growth regulators (see subsequently). The $\mathrm{pH}$ was adjusted to 5.8 with $1 \mathrm{~m} \mathrm{NaOH}$ before autoclaving at $121{ }^{\circ} \mathrm{C}$ for 20 to $25 \mathrm{~min}$. The media were dispensed into $90 \mathrm{~mm}$ petri dishes $(25 \mathrm{~mL}$ of medium per dish), in the case of callus induction, or plastic boxes $(250 \mathrm{~mL}$, made in China; $40 \mathrm{~mL}$ per box) for shoot induction, shoot elongation, and rooting procedures.

Experiments of callus induction from cotyledon explants were performed on half-strength MS media supplemented with various levels of benzyladenine (BA), dichlophenoxyacetic acid (2,4-D), 1-naphthaleneacetic acid (NAA), and indolebutyric acid (IBA) supplied in 11 combinations (see Table 1). To stimulate adventitious shoot induction, callus outgrowths were transferred to various media supplemented with various levels of either BA and NAA or thidiazuron (TDZ) and IBA (Table 2).

All the cultures (unless stated otherwise) were maintained in a growth chamber at $25 \pm 2{ }^{\circ} \mathrm{C}$ under a 14 -h photoperiod of $50 \mu \mathrm{mol} \cdot \mathrm{m}^{-2} \cdot \mathrm{s}^{-1}$ of photosynthetic photon flux $(P P F)$.

Effect of callus source and light on shoot induction. It was found that half-strength MS medium supplemented with $2.2 \mu \mathrm{M}$ BA, 10.0 $\mu \mathrm{M}$ NAA, and 5.0 $\mu \mathrm{M}$ IBA produced the most vigorous callus growth, and half-strength MS medium supplemented with $2.2 \mu \mathrm{M}$ BA, $2.2 \mu \mathrm{M} \mathrm{TDZ}$, and $1.0 \mu \mathrm{M}$ IBA yielded the highest number of shoots. Therefore, these two media were used in all further experiments designed to test the effects of callus source and light conditions on rates of plant regeneration.

Shoot elongation, rooting, and acclimatization. To promote elongation growth of shoots, the regenerated buds were cultured on WPM medium (Lloyd and McCown, 1980) supplemented with $2.2 \mu \mathrm{M}$ BA, $0.45 \mu \mathrm{M}$ TDZ, and $1.0 \mu \mathrm{M}$ IBA. After incubation for 3 weeks, the most vigorous shoots were cut at the base and transferred 
to a WPM medium supplemented with 2.5 or $5.0 \mu \mathrm{M}$ IBA and incubated under lights to induce rooting. After 6 weeks, rooted plantlets (defined as having at least one root greater than $10 \mathrm{~mm}$ in length) were washed thoroughly with running tap water, to remove the culture medium, and transplanted into plastic pots containing a mixture of 2 peatmoss : 2 garden soil : 1 sand (by volume). These were then kept in a growth chamber set to $70 \%$ relative humidity and $19{ }^{\circ} \mathrm{C}$. After 2 weeks, the pots were transferred to a greenhouse and maintained at average $19{ }^{\circ} \mathrm{C}$ for further development.

Statistical analysis. For callus induction, seven explants were incubated under each treatment regimen. Experiments of callus initiation and shoot induction were repeated at least three times. The differences between mean values (obtained from at least two independent experiments) were statistically evaluated by analysis of variance (ANOVA) using Duncan's multiple-range test with the least significant difference set to $5 \%$ probability.

\section{Results}

Callus initiation. No callus was obtained when immature cotyledons of $P$. mume (Fig. 1A) were cultured on a medium that was free from plant growth regulators or contained less than $2.7 \mu \mathrm{M}$ NAA or 2.2 or less BA. However, calli (Fig. 1B) could be obtained when explants were cultured on half-strength MS supplemented with different concentrations of either BA, NAA, and IBA or BA, 2,4-D, and IBA (Tables 1 and 2). There were significant differences $(P<0.05)$ in the percentage of callus induction resulting from incubation of cotyledon explants on the various media. Across the combinations of plant growth hormones tested and the two cultivars of $P$. mume, the percentage of callus formation varied from $22 \%$ to $97 \%$ (Table 1 ). Growth of callus that was induced on various media varied considerably with respect to physical appearance and could be classified into three general types, i.e., $1=$ light yellow, loose and globular; $2=$ smooth white, loose and nodular (Fig. 1B); or $3=$ light yellow, hard and globular.

Shoot regeneration from callus. In the most part, shoots regenerated through organogenesis were derived from the type 2 form of callus (see previously) (Fig. 1B) that had either originated from cotyledons or were from primary callus cultures. These calli maintained their morphogenetic potential for at least two rounds of subculturing. When these calli were cultured on half-strength MS supplemented with $2.7 \mu \mathrm{M}$ NAA and 13.2 to $22.0 \mu_{\mathrm{M}} \mathrm{BA}$, small regenerated shoots (Fig. 1C, D) were observed to form on the callus after 4 weeks, but this tended to occur at fairly low frequencies. The further incorporation of TDZ in the regeneration medium significantly stimulated shoot regeneration. Thus, a medium supplemented with $2.2 \mu \mathrm{M}$ BA and $1.0 \mu \mathrm{M}$ IBA plus $2.25 \mu \mathrm{M}$ TDZ

Table 1. Response of callus induction to plant growth regulators in immature Prunus mume cotyledons (cultivars Xuemei and Lv'e) on half-strength MS medium. ${ }^{\mathrm{z}}$

\begin{tabular}{|c|c|c|c|c|c|}
\hline \multicolumn{4}{|c|}{ Plant growth regulators $(\mu \mathrm{M})$} & \multicolumn{2}{|c|}{ Percentage of explants forming callus (\%) } \\
\hline$\overline{\mathrm{BA}}$ & $2,4-\mathrm{D}$ & NAA & $\overline{\text { IBA }}$ & Lv'e & Xuemei \\
\hline$\overline{2.2}$ & 0 & 0 & 0 & 0 & 0 \\
\hline 2.2 & 0 & 5.4 & 0 & $22.2 \pm 3.1 \mathrm{e}$ & $43.0 \pm 4.2 \mathrm{e}$ \\
\hline 2.2 & 0 & 5.4 & 2.5 & $55.0 \pm 7.1 \mathrm{~d}$ & $53.0 \pm 4.2 \mathrm{de}$ \\
\hline 2.2 & 0 & 5.4 & 5.0 & $74.9 \pm 2.2 \mathrm{c}$ & $67.5 \pm 10.6 \mathrm{dc}$ \\
\hline 2.2 & 0 & 10.8 & 0 & $80.0 \pm 1.0 \mathrm{bc}$ & $85.0 \pm 1.4 \mathrm{abc}$ \\
\hline 2.2 & 0 & 10.8 & 2.5 & $97.0 \pm 1.4 \mathrm{a}$ & $97.5 \pm 3.5 \mathrm{a}$ \\
\hline 2.2 & 0 & 10.8 & 5.0 & $95.0 \pm 7.1 \mathrm{a}$ & $90.0 \pm 4.2 \mathrm{abc}$ \\
\hline 2.2 & 4.5 & 0 & 2.5 & $81.6 \pm 2.3 b c$ & $95.5 \pm 6.4 \mathrm{abc}$ \\
\hline 2.2 & 9.0 & 0 & 2.5 & $91.6 \pm 11.8 \mathrm{ab}$ & $85.0 \pm 7.0 \mathrm{abc}$ \\
\hline 2.2 & 4.5 & 0 & 5.0 & $81.5 \pm 3.0 \mathrm{bc}$ & $75.0 \pm 7.1 \mathrm{bc}$ \\
\hline 2.2 & 9.0 & 0 & 5.0 & $71.5 \pm 2.1 \mathrm{c}$ & $50.0 \pm 14 \mathrm{de}$ \\
\hline
\end{tabular}

${ }^{2}$ Values (mean \pm standard error) with the same letter within a column are not significantly different at $P=0.05$ (Duncan's multiple range test).

$\mathrm{BA}=$ benzyladenine; 2,4-D, dichlophenoxyacetic acid; $\mathrm{NAA}=1$-naphthaleneacetic acid; $\mathrm{IBA}=$ indolebutyric acid.

Table 2. Percentage of regeneration from cotyledon-derived callus in relation to plant growth regulators used with half-strength MS medium for two Prunus mume cultivars (Xuemei and Lv'e). ${ }^{\mathrm{z}}$

\begin{tabular}{lllllcc}
\hline & \multicolumn{2}{c}{ Plant growth regulators $(\mu \mathrm{M})$} & & & \multicolumn{2}{c}{ Percentage of calli forming shoots $(\%)$} \\
\cline { 1 - 2 } \cline { 6 - 7 } & TDZ & NAA & IBA & & Lv'e & Xuemei \\
\hline 4.4 & 0 & 2.7 & 0 & 0 & 0 \\
8.8 & 0 & 2.7 & 0 & & 0 & 0 \\
13.2 & 0 & 2.7 & 0 & $27.8 \pm 7.4 \mathrm{~b}$ & $50.0 \pm 7.1 \mathrm{~cd}$ \\
17.6 & 0 & 2.7 & 0 & $36.5 \pm 5.0 \mathrm{~b}$ & $63.4 \pm 2.4 \mathrm{bc}$ \\
22.0 & 0 & 2.7 & 0 & & $73.4 \pm 9.4 \mathrm{a}$ & $73.4 \pm 4.7 \mathrm{ab}$ \\
2.2 & 0.45 & 0 & 1.0 & & $32.5 \pm 10.6 \mathrm{~b}$ & $36.7 \pm 2.4 \mathrm{~d}$ \\
2.2 & 2.25 & 0 & 1.0 & & $81.5 \pm 2.1 \mathrm{a}$ & $91.3 \pm 2.7 \mathrm{a}$ \\
2.2 & 4.50 & 0 & 1.0 & $74.3 \pm 10.8 \mathrm{a}$ & $65.0 \pm 3.5 \mathrm{bc}$ \\
\hline
\end{tabular}

${ }^{2}$ Data were collected 6 weeks after transferring the callus to the medium on which they were cultured for the first 2 weeks in the dark and then transferred to light. Values (mean \pm standard error) within a column followed by the different letters are significantly different at $P=0.05$ (Duncan's multiple range test). $\mathrm{BA}=$ benzyladenine; $\mathrm{TDZ}=$ thidiazuron; NAA = 1-naphthaleneacetic acid; IBA = indolebutyric acid.
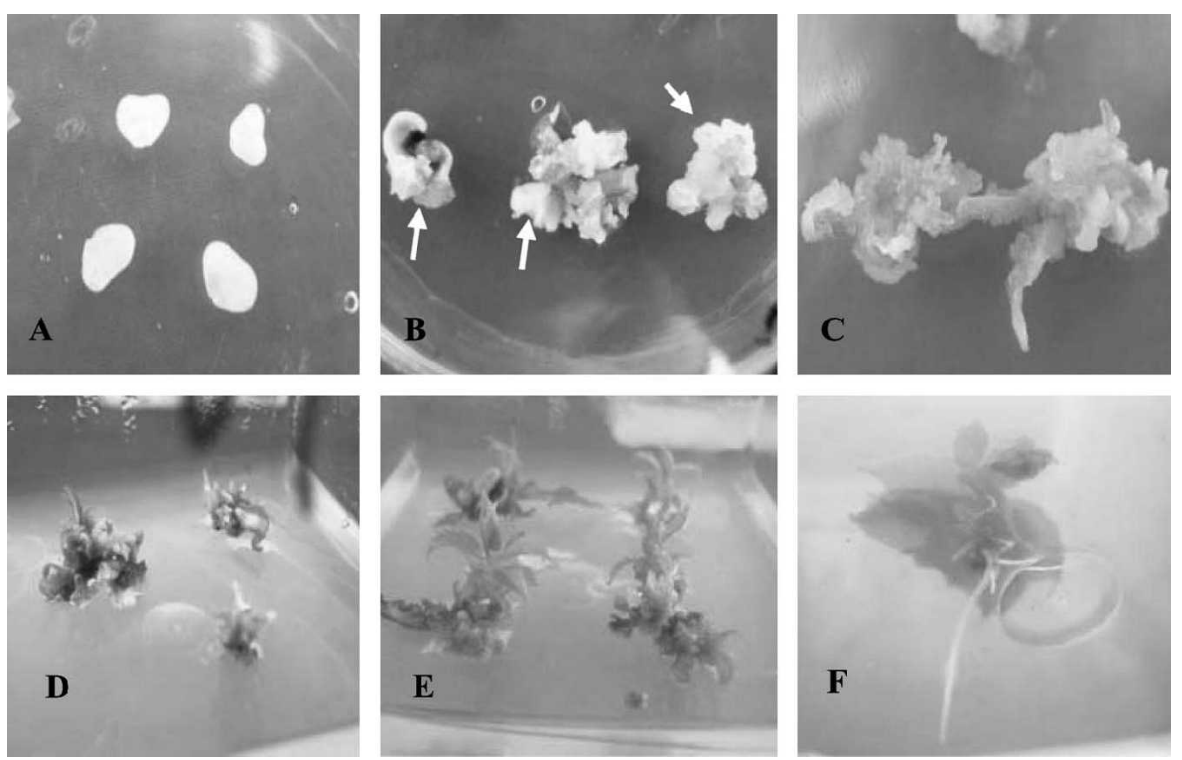

Fig. 1. Plant regeneration through shoot organogenesis from callus derived from cotyledons of immature embryos of Prunus mume: (A) Cotyledons from P. mume immature embryos. (B) Calli formed from the cotyledon explants (arrow). (C) Shoots regenerated from smooth white nodular calli of cotyledon explants in darkness. (D) Shoots regenerated from smooth-white nodular calli under light. (E) Shoot elongation. (F) Rooting (view of the bottom of plastic box).

produced the maximal regeneration frequencies of $81.5 \%$ and $91.3 \%$ in the 'Lv'e' and 'Xuemei' cultivars, respectively (Table 2). No significant difference in regeneration frequency was detected between calli initiated from the proximal or distal sections of the cotyledons for either cultivar (Table 3). By contrast, the ambient light environment produced different regeneration responses in the two cultivars (Table 4). In 'Lv'e', regeneration frequency did not differ significantly under light compared with dark conditions 
as tested by ANOVA analysis $(P<0.05)$. In 'Xuemei'; however, it was apparent that continuous darkness was beneficial for regeneration (Table 4).

Shoot elongation, rooting, and acclimatization. After growth in elongation medium for $\approx 3$ weeks, shoots at least $1 \mathrm{~cm}$ in length (Fig. 1E) were cut and transferred to rooting medium. Within 4 weeks, these shoots had produced roots from the base of the excision site (Fig. 1F). The number of shoots that produced one or more roots (according to 50 tested shoots) and the number of roots (greater than $5 \mathrm{~mm}$ in length) per shoot differed significantly when cultured on WPM media as supplemented with 2.5 or $5.0 \mu \mathrm{M}$ IBA (Table 5). By contrast, there was no significant difference between the two cultivars at a given concentration of IBA. After 6 weeks of rooting initiation, the plantlets were transferred to soil for "hardening." The survival rate of these regenerated plantlet was greater than $90 \%$ under greenhouse conditions.

\section{Discussion}

This is the first report, to our knowledge, of the successful in vitro regeneration of $P$. mume through organogenesis from callus derived from immature cotyledons.

In Prunus species, somatic embryogenesis has been the most commonly reported regeneration pathway (Cheong and Pooler, 2004; Hashmi et al., 1997; Tang et al., 2000). Directive shoot differentiation had been reported from immature cotyledons of almond (Phillip et al., 2001; Saafi and Dulal, 2002) and some other woody plant cultures (Tan and Furtek, 2003; Wei et al., 2005). In this study of Prunus mume, it was possible to obtain abundant callus from immature embryos cultured on a medium supplemented with specific concentrations of plant growth regulators (Table 1), and shoots could be readily regenerated from the smoothwhite nodular form of callus. This result is consistent with that reported for peach (Hammerschlag et al., 1985; Hashmi et al., 1997). During callus induction, increasing the concentration of NAA (in a medium also containing $2.2 \mu \mathrm{M}$ BA) increased the percentage of callus formation (Table 1) and furthermore eliminated the secretion of phenolic substances from the cut surface of the cotyledons. This observation is consistent with Olaya et al. (2000) who reported that such phenolic substances are particularly liable to be oxidized by auxin oxidase when there is a high concentration of NAA in the culture medium. Callus was also readily obtained on media supplemented with $2.2 \mu \mathrm{M} \mathrm{BA}$ in combination with either of two auxins, i.e., NAA or 2,4-D and IBA. A high level of 2,4-D $(9.0 \mu \mathrm{M})$ in combination with a low level of BA and IBA (2.2 and $1.0 \mu \mathrm{M}$, respectively) led to high callus yields. This was contrary to reports in other plant species (Luo et al., 1999; Nolan et al., 1989). Previous reports of other Prunus species have indicated that plantlet regeneration from leaves shows that WPM basic medium is more suitable for the induction of adventitious shoots than is MS basal medium (Andrea and Johannes, 2005;
Bhagwat and David, 2004; Hammatt and Grant, 1998; Neil and Neil, 2000; Tang et al., 2002). However, a high frequency regeneration of $P$. mume was obtained from organogenic callus derived from cotyledons that had been cultured on half-strength MS media supplemented with $2.2 \mu \mathrm{M}$ BA, $2.25 \mu \mathrm{M}$ TDZ, and $1.0 \mu \mathrm{M}$ IBA. There was no difference in regeneration frequency from those calli derived from the distal, as opposed to proximal, parts of the cotyledons (Table 3 ). This is in contrast to observations from other Prunus species (Mante et al., 1989; Tang et al., 2000).

With regard to the frequency of shoot organogenesis from calli derived from the 'Xuemei' cultivar, the effect of a light versus dark incubation was significant (Table 4). In 'Lv'e', there was no significant effect. This result indicates that the importance of the light environment on shoot organogenesis from cotyledon-derived calli is genotype-dependent.

Recently, successful genetic transformation has been reported for a number of plant species through the use of cotyledon explants (Choi et al., 2001, Zaragoz et al., 2004), and transgenic plants have been obtained for some other Prunus species (Rosa et al., 2004). Here, we have described the culture conditions that can produce an efficient frequency of plantlet regeneration from immature cotyledon explants of Prunus mume. The regeneration method presented here is an essential basis for the introduction of heterologous genes through Agrobacterium-mediated transformation for the genetic improvement of this important tree species.
Table 3. Effect of explant source (proximal or distal to the embryonic axis) on adventitious shoot formation of two cultivars (Xuemei and Lv'e) of Prunus mume. ${ }^{z}$

\begin{tabular}{llc}
\hline Cultivar & Source of callus & Percentage of calli forming shoots (\%) \\
\hline Lv'e & Distal section & $85.5 \pm 8.0 \mathrm{a}$ \\
& Proximal section & $75.8 \pm 13.0 \mathrm{a}$ \\
Xuemei & Distal section & $81.0 \pm 13.0 \mathrm{a}$ \\
& Proximal section & $87.5 \pm 11.0 \mathrm{a}$ \\
\hline
\end{tabular}

${ }^{2}$ Data were collected 5 weeks after transferring callus to shoot formation medium. Values (mean \pm standard error) within a cultivar followed by different letters are significantly different at $P=0.05$ (Duncan's multiple range test).

Table 4. Effect of light on adventitious shoot formation from cotyledon explants of the Xuemei and Lv'e cultivars of Prunus mume. ${ }^{\mathrm{z}}$

\begin{tabular}{lcc}
\hline Cultivar & Light condition & Percentage of callus forming shoots (\%) \\
\hline Lv'e & Light & $56.3 \pm 14.6 \mathrm{~b}$ \\
& Dark & $73.4 \pm 9.4 \mathrm{ab}$ \\
Xuemei & Light & $63.4 \pm 4.7 \mathrm{~b}$ \\
& Dark & $91.3 \pm 5.3 \mathrm{a}$ \\
\hline
\end{tabular}

${ }^{\mathrm{z}}$ Data were collected after 6 weeks after transferring callus to shoot formation medium in different light conditions. Values (mean \pm standard error) followed by different letters within a cultivar are significantly different at $P=0.05$ (Duncan's multiple range test).

Table 5. Rooting of Prunus. mume Xuemei and Lv'e after 4 weeks of culture on different media. ${ }^{2}$

\begin{tabular}{llcc}
\hline Rooting media & Cultivar & Rooting percentage (\%) & $\begin{array}{c}\text { Number of roots per shoot } \\
\text { (greater than 5 mm) }\end{array}$ \\
\hline WPM + $2.5 \mu \mathrm{M}$ IBA & Xuemei & $81.2 \pm 1.5 \mathrm{~b}$ & $2.34 \pm 0.1 \mathrm{~b}$ \\
& Lv'e & $80.3 \pm 1.2 \mathrm{~b}$ & $2.16 \pm 0.05 \mathrm{~b}$ \\
WPM $+5.0 \mu \mathrm{M}$ IBA & Xuemei & $88.9 \pm 1.5 \mathrm{a}$ & $3.96 \pm 1.0 \mathrm{ab}$ \\
& Lv'e & $90.2 \pm 2.2 \mathrm{a}$ & $5.25 \pm 1.7 \mathrm{a}$ \\
\hline
\end{tabular}

${ }^{\mathrm{z}}$ Values (mean \pm standard error) followed by different letters within a column are significantly different at $P=0.05$ (Duncan's multiple range test).

\section{Literature Cited}

Andrea, M. and A.J. Johannes. 2005. In vitro plant regeneration from leaves and internode sections of sweet cherry cultivars (Prunus avium. L). Plant Cell Rep. 24:468-476.

Bhagwat, B. and W.L. David. 2004. In vitro shoot regeneration from leaves of sweet cherry (Prunus avium) 'Lapins' and 'Sweetheart'. Plant Cell Tissue Organ Cult. 78: 173-181.

Chen, J.Y. 1962. Studies of Chinese Mei (Prunus mume Sieb. et Zucc) - The origin and cultivation history. Acta Horticulturae Sinica. 1: 69-78.

Cheong, E.J. and M.R. Pooler. 2004. Factors affecting somatic embryogenesis in Prunus incisa cv. February Pink. Plant Cell Rep. 22:810-815

Choi, Y.E., D.C. Yang, T. Kusano, and H. Sano. 2001. Rapid and efficient Agrobacterium mediated transformation of Panax ginseng by plasmolyzing pre-treatment of cotyledons. Plant Cell Rep. 20:616-621.

Declerck, V. and S.S. Korban. 1996. Influence of growth regulators and carbon sources on callus induction, growth and morphogenesis from leaf tissues of peach (Prunus persica L. Batsch). HortScience 71:49-55.

Dogasaki, C., Y. Kakuno, M. Honda, N. Takada, T. Maruyama, M. Nishijima, Y. Adachi, N. Ohno, T. Yadomae, and T. Miyazaki. 2004. Contribution to Immunochemical Analysis of Polysaccharides in Medicinal Plants. Drug Design Reviews 1:153-159. 
Entani, T., M. Iwano, H. Shiba, F.S. Che, A. Isogai, and S. Takayama. 2003. Comparative analysis of the self-incompatibility $(S$-) locus region of Prunus mume: Identification of a pollenexpressed F-box gene with allelic diversity. Genes Cells 8:203-213.

Gentile, A., S. Monticelli, and C. Damiano. 2002. Adventitious shoot regeneration in peach [Prunus persica (L.) Batsch]. Plant Cell Rep. 20:1011-1016.

Hammatt, N. and N.J. Grant. 1998. Shoot regeneration from leaves of Prunus serotina Ehrh. (black cherry) and $P$. avium L. (wild cherry). Plant Cell Rep. 17:526-530.

Hammerschlag, F.A., G. Bauchan, and R. Scorza. 1985. Regeneration of peach plants from callus derived from immature embryos. Theor. Appl. Genet. 70:248-251.

Hashmi, G., R. Huettel, R. Meyer, L. Krusberg, and F. Hammerschlag. 1997. RAPD analysis of somaclonal variants derived from embryo callus cultures of peach. Plant Cell Rep. 16:624 627.

Hokanson, K.E. and M.R. Pooler. 2000. Regeneration of ornamental cherry (Prunus) taxa from mature stored seed. HortScience 35:745-748.

Liu, Q.L. and Q.H. Chen. 1999. Preliminary reports of callus culture on Prunus mume. Journal of Beijing Forestry University. 21:400-405.

Lloyd, G.B. and B.H. McCown. 1980. Commercially feasible micropropagation of mountain laurel, Kalmia latifolia, by use of shoot-tip culture. Proc Int Plant Prop Soc. 30:421-427.
Luo, J.P., J.F. Jia, Y.H. Gu, and J. Liu. 1999. High frequency somatic embryogenesis and plant regeneration in callus cultures of Astragalus adsurgens. Pall. Plant Sci. 143:93-99.

Mante, S., R. Scorza, and J.M. Cordts. 1989. Plant regeneration from cotyledons of Prunus persica, Prunus domestica, and Prunus cerasus. Plant Cell Tissue Organ Cult. 19:1-11.

Murashige, T. and F. Skoog. 1962. A revised media for rapid growth and bioassays with tobacco tissue cultures. Physiol. Plant. 15:473-497.

Neil, J.G. and H. Neil. 2000. Adventitious shoot development from wild cherry (Prunus avium L.) leaves. New For. 20:287-295.

Nolan, K.E., R.J. Rose, and J.R. Gost. 1989. Regeneration of Medicago truncatula from tissue culture: Increased somatic embryogenesis using explants from regenerated plant. Plant Cell Rep. 8:279-281.

Olaya, P.T., E. Jose, V. Alicia, and B. Lorenzo. 2000. Assessment of factors affecting adventitious shoot regeneration from in vitro cultured leaves of apricot. Plant Sci. 158:61-70.

Phillip, J.A., A.H. Freddi, B. Terry, G.C. Graham, and S. Margaret. 2001. Regeneration of almond from immature seed cotyledons. Plant Cell Tissue Organ Cult. 67:221-226.

Pooler, M.R. and R. Scorza. 1995. Regeneration of peach [Prunus persica (L.) Batsch] rootstock cultivars from cotyledons of mature stored seed. HortScience 30:355-356.

Rosa, M.P.C., P.S. Amparo, G.F. Lorenzo, B. JoséPío, and A.C. Luis. 2004. Transgenic peach plants (Prunus persica L.) produced by genetic transformation of embryo sections using the green fluorescent protein (GFP) as an in vivo marker. Mol. Breed. 14:419-427.

Saafi, H. and B. Dulal. 2002. In vitro plantlet regeneration from cotyledons of the treelegume Leucaena leucocephala. Plant Growth Regul. 38:279-285.

Tan, C.L. and D.B. Furtek. 2003. Development of an in vitro regeneration system for Theobroma cacao from mature tissues. Plant Sci. 164:407412.

Tang, H., Z.L. Ren, and K. Gabi. 2000. Somatic embryogenesis and organogenesis from immature embryo cotyledons of three sour cherry cultivars (Prunus cerasus L.). Sci. Hort. 83:109-126.

Tang, H., Z.L. Ren, G. Reustle, and G. Krczal. 2002. Plant regeneration from leaves of sweet and sour cherry cultivars. Sci. Hort. 93:235244.

Tao, R., T. Habu, and H. Yamane. 2000. Molecular markers for self-compatibility in Japanese apricot (Prunus mume). HortScience 35:121123.

Wei, T. and R.J. Newton. 2005. Plant regeneration from callus cultures derived from mature zygotic embryos in white pine (Pinus strobus L.). Plant Cell Rep. 24:1-9.

Zaragoz, C., J. Mu, and A. Bertomeu. 2004. Regeneration of herbicide-tolerant black locust transgenic plants by SAAT. Plant Cell Rep. 22:832-838. 